\title{
Kinetic effects of carbon monoxide inhalation on tissue protection in ventilator-induced lung injury
}

\author{
Simone Faller ${ }^{1}$, Michael Foeckler ${ }^{1}$, Karl M Strosing ${ }^{1}$, Sashko Spassov ${ }^{1}$, Stefan W Ryter ${ }^{2}$, Hartmut Buerkle ${ }^{1}$, \\ Torsten Loop ${ }^{1}$, Rene Schmidt ${ }^{1}$ and Alexander Hoetzel ${ }^{1}$
}

Mechanical ventilation causes ventilator-induced lung injury (VILI), and contributes to acute lung injury/acute respiratory distress syndrome (ALI/ARDS), a disease with high morbidity and mortality among critically ill patients. Carbon monoxide (CO) can confer lung protective effects during mechanical ventilation. This study investigates the time dependency of CO therapy with respect to lung protection in animals subjected to mechanical ventilation. For this purpose, mice were ventilated with a tidal volume of $12 \mathrm{ml} / \mathrm{kg}$ body weight for $6 \mathrm{~h}$ with air in the absence or presence of CO (250 parts per million). Histological analysis of lung tissue sections was used to determine alveolar wall thickening and the degree of lung damage by VILI score. Bronchoalveolar lavage fluid was analyzed for total cellular influx, neutrophil accumulation, and interleukin- $1 \beta$ release. As the main results, mechanical ventilation induced pulmonary edema, cytokine release, and neutrophil recruitment. In contrast, application of $\mathrm{CO}$ for $6 \mathrm{~h}$ prevented VILI. Although $\mathrm{CO}$ application for $3 \mathrm{~h}$ followed by 3-h air ventilation failed to prevent lung injury, a further reduction of $\mathrm{CO}$ application time to $1 \mathrm{~h}$ in this setting provided sufficient protection. Pre-treatment of animals with inhaled $\mathrm{CO}$ for $1 \mathrm{~h}$ before ventilation showed no beneficial effect.

Delayed application of $\mathrm{CO}$ beginning at 3 or $5 \mathrm{~h}$ after initiation of ventilation, reduced lung damage, total cell influx, and neutrophil accumulation. In conclusion, administration of $\mathrm{CO}$ for $6 \mathrm{~h}$ protected against VILI. Identical protective effects were achieved by limiting the administration of $\mathrm{CO}$ to the first hour of ventilation. Pre-treatment with CO had no impact on VILI. In contrast, delayed application of CO led to anti-inflammatory effects with time-dependent reduction in tissue protection. Laboratory Investigation (2012) 92, 999-1012; doi:10.1038/labinvest.2012.55; published online 26 March 2012

KEYWORDS: carbon monoxide; heme oxygenase; organ protection; ventilator-induced lung injury

Mechanical ventilation is commonly used as a supportive strategy in critical care medicine. Unfortunately, mechanical ventilation can contribute to the development of acute lung injury/acute respiratory distress syndrome (ALI/ARDS). Modification of ventilator settings have improved the clinical outcome of patients suffering from ARDS. ${ }^{1,2}$ Unfortunately and despite the implementation of protective ventilatory strategies over the last decade, mechanical ventilation still may lead to ventilator-induced lung injury (VILI) or aggravate pre-existing lung injury. Hence, the current high morbidity and mortality among ALI/ARDS patients still urgently requires the development of additional strategies that would minimize the risk for VILI.

VILI is characterized by a series of biotraumatic events. Depending on the local force in the lung as well as any preexisting vulnerability of this organ, mechanical stretching of lung tissue caused by mechanical ventilation can lead to the disruption of the alveolar-capillary barrier, pulmonary edema formation, increased oxidative stress, and significant inflammatory responses. Key features of inflammation subsequent to mechanical ventilation include the influx of immune-competent cells, in particular neutrophils, and the release of pro-inflammatory cytokines, such as interleukin- $1 \beta$ (IL-1 $\beta)$ or macrophage inflammatory protein-1.,4 Subsequently, local lung inflammation may also affect other organs, leading to the development of multiple organ failure. ${ }^{2}$

The development of strategies to limit or even prevent the inflammatory response to mechanical ventilation, including experimental therapies using small gaseous molecules such as carbon monoxide (CO), have gained considerable interest. CO is an odorless, low-molecular-weight gas, which is well known for its toxic properties at high concentrations. ${ }^{5,6}$ However, CO

\footnotetext{
${ }^{1}$ Department of Anesthesiology and Critical Care Medicine, University Medical Center Freiburg, Freiburg, Germany and ${ }^{2}$ Department of Pulmonary and Critical Care Medicine, Brigham and Women's Hospital, Harvard Medical School, Boston, MA, USA

Correspondence: Dr A Hoetzel, MD, MA, Department of Anesthesiology and Critical Care Medicine, University Medical Center Freiburg, Hugstetter Str. 55, D-79106 Freiburg, Germany.

E-mail: alexander.hoetzel@uniklinik-freiburg.de

Received 5 August 2011; revised 3 February 2012; accepted 21 February 2012
} 
can evolve endogenously, mainly as the product of heme degradation catalyzed by heme oxygenase (HO; E.C. 1:14:99:3) enzymes. $^{7-9}$ Upregulation of the inducible isoform of $\mathrm{HO}$, $\mathrm{HO}-1$, limits pro-inflammatory processes, in part through the generation of $\mathrm{CO} .^{10,11}$ In fact, exogenous application of $\mathrm{CO}$ can mimic the protective effects of HO-1 upregulation, even when this enzyme activity was chemically blocked. ${ }^{12,13}$ Moreover, treatment with inhaled $\mathrm{CO}$ or CO-releasing molecules (CORMs) prevented ischemia-reperfusion injury, ${ }^{14-16}$ hyperoxia-induced injury, ${ }^{17,18}$ sepsis, ${ }^{19,20}$ or organ transplant rejection $^{21-24}$ in several in vivo and in vitro models. Recently, we and others could demonstrate that inhalation of $\mathrm{CO}$ at low concentration limits the inflammatory response upon mechanical ventilation, thus preventing VILI in these animals. ${ }^{25-27}$ With respect to the mechanisms underlying organ protection by $\mathrm{CO}$, multiple signaling pathways have been described, including mitogen-activated protein kinases (MAPKs), caveolin-1, early growth response gene-1 (Egr-1), peroxisome proliferator-activated receptor- $\gamma$, heat shock proteins, and others. ${ }^{26,27}$

Based on the fact that many laboratory reports demonstrated dose-response relationships in the mechanisms of $\mathrm{CO}$ action, it is somewhat surprising that currently little is known about the time dependency of CO administration. Regarding potential future clinical implications and potential side effects of $\mathrm{CO}$ application, it is rather important to define the kinetic aspects of CO-dependent cytoprotection, its efficacy as a pre-treatment option, and its usefulness as a post-injury therapeutic. In the current studies, we determine the essential role of timing for $\mathrm{CO}$-mediated lung protection in a mouse model of VILI.

\section{MATERIALS AND METHODS Animals}

Male C57BL/6N mice were obtained from Charles River Laboratories (Sulzburg, Germany) and used at a body weight of $22-25 \mathrm{~g}$. All animal experiments were performed in accordance with the guidelines of the local animal care commission (ethics committee of the University of Freiburg, permission No. G-07/25). All mice were anesthetized with ketamine $(90 \mathrm{mg} / \mathrm{kg}$, intraperitoneal (i.p.), and acepromazine $(0.9 \mathrm{mg} / \mathrm{kg}$, i.p.) and placed on a $36.5^{\circ} \mathrm{C}$ warm heating pad to maintain normal body temperature (measured with a rectal thermoelement). A polyethylene catheter was inserted into the left carotid artery for direct blood pressure monitoring as well as for blood gas sampling, and a tracheotomy was established using a 20-gauge catheter. While non-ventilated control mice were subjected to the instrumentation after $6 \mathrm{~h}$ spontaneous breathing room air and being sacrificed immediately after, mice randomized to receive mechanical ventilation, were connected to a rodent ventilator (Voltek Enterprises, Toronto, Canada) via a tracheal cannula and ventilated with synthetic air. In the case of $\mathrm{CO}$ supplementation (Air Liquide, Kornwestheim, Germany), a concentration of 250 parts per million (p.p.m.) was used and continuously monitored during ventilation. The ventilator was set to a tidal volume of
$12 \mathrm{ml} / \mathrm{kg}$ body weight, frequency $80-90 / \mathrm{min}$, and positive endexpiratory pressure of $2 \mathrm{cmH} 2 \mathrm{O}$. Muscular relaxation was achieved by applying pancuronium $(2 \mathrm{mg} / \mathrm{kg}$, i.p.). Anesthesia was maintained by continuous administration of ketamine, acepromazine, and pancuronium i.p. as needed. A $0.7-\mathrm{ml}$ saline bolus was injected i.p. to compensate for evaporation during ventilation. Blood samples were withdrawn from ventilated animals after 30-45 min and $\mathrm{pH}, \mathrm{PaCO}_{2}, \mathrm{PaO}_{2}$, and $\mathrm{COHb}$ were measured using an automated blood gas analyzer (ABL600/800, Radiometer, Copenhagen, Denmark) to ensure normal ventilation and without showing any differences between treatment groups regarding $\mathrm{pH}, \mathrm{PaO}_{2}$, and $\mathrm{PaCO}_{2}$ (data not shown). Another blood sample was taken after $6 \mathrm{~h}$ at the end of ventilation and blood gases and $\mathrm{COHb}$ were again analyzed. Recruitment maneuvers (inspiratory hold on $30 \mathrm{cmH} 2 \mathrm{O}$ for $5 \mathrm{~s}$ ) were performed every $60 \mathrm{~min}$ during ventilation to prevent atelectasis. Body temperature $\left(\mathrm{Tb}\left({ }^{\circ} \mathrm{C}\right)\right)$, arterial blood pressure $(\mathrm{mmHg})$, peak airway pressure and plateau airway pressure $(\mathrm{cmH} 2 \mathrm{O})$, were continuously monitored (PowerLab 3/80, ADInstruments, Spechbach, Germany) and recorded every $30 \mathrm{~min}$. Total respiratory system compliance was calculated as described previously. ${ }^{28}$ Tidal volume was divided by the difference between the end-inspiratory and end-expiratory plateau pressures for each time point recorded.

\section{Experimental Groups}

The study consisted of four independent sets of experiments, $n=6-7 /$ group (Figure 1). (I) First set of experiments (Figure 1a): non-ventilated control mice were allowed to breathe air spontaneously. Mice receiving mechanical ventilation were randomized to ventilation with either synthetic air or synthetic air supplemented with 250 p.p.m. CO for $6 \mathrm{~h}$. (II) Second set of experiments (Figure 1b): non-ventilated control mice were allowed to breathe air spontaneously. Mechanically ventilated mice were randomized to either ventilation with synthetic air for $6 \mathrm{~h}$; ventilation with $\mathrm{CO}$ for the first hour, followed by ventilation with air for $5 \mathrm{~h}$, ventilation with $\mathrm{CO}$ for $3 \mathrm{~h}$ followed by ventilation with air for $3 \mathrm{~h}$; or ventilation with $\mathrm{CO}$ for $6 \mathrm{~h}$. (III) Third set of experiments (Figure 1c): non-ventilated control mice were allowed to breathe air spontaneously. Mechanically ventilated mice were randomized to ventilation with synthetic air for $6 \mathrm{~h}$ with spontaneous breathing of air or 250 p.p.m. CO in a sealed chamber for $1 \mathrm{~h}$ before ventilation; or ventilation with $\mathrm{CO}$ for $6 \mathrm{~h}$. (IV) Fourth set of experiments (Figure 1d): nonventilated control mice were allowed to breathe air spontaneously. Mechanically ventilated mice were randomized to ventilation with synthetic air for $6 \mathrm{~h}$; ventilation with air for $5 \mathrm{~h}$ followed by 1 - $\mathrm{h}$ ventilation with $\mathrm{CO}$; ventilation with air for $3 \mathrm{~h}$ followed by 3 -h ventilation with $\mathrm{CO}$; or ventilation with $\mathrm{CO}$ for $6 \mathrm{~h}$. In addition, ventilation was performed in another five groups. Here, $\mathrm{CO}$ treatment was started as late as $5 \mathrm{~h}$ after the onset of ventilation, and total experimental time was extended to 8 or $10 \mathrm{~h}$ (Supplementary Figure 1). 

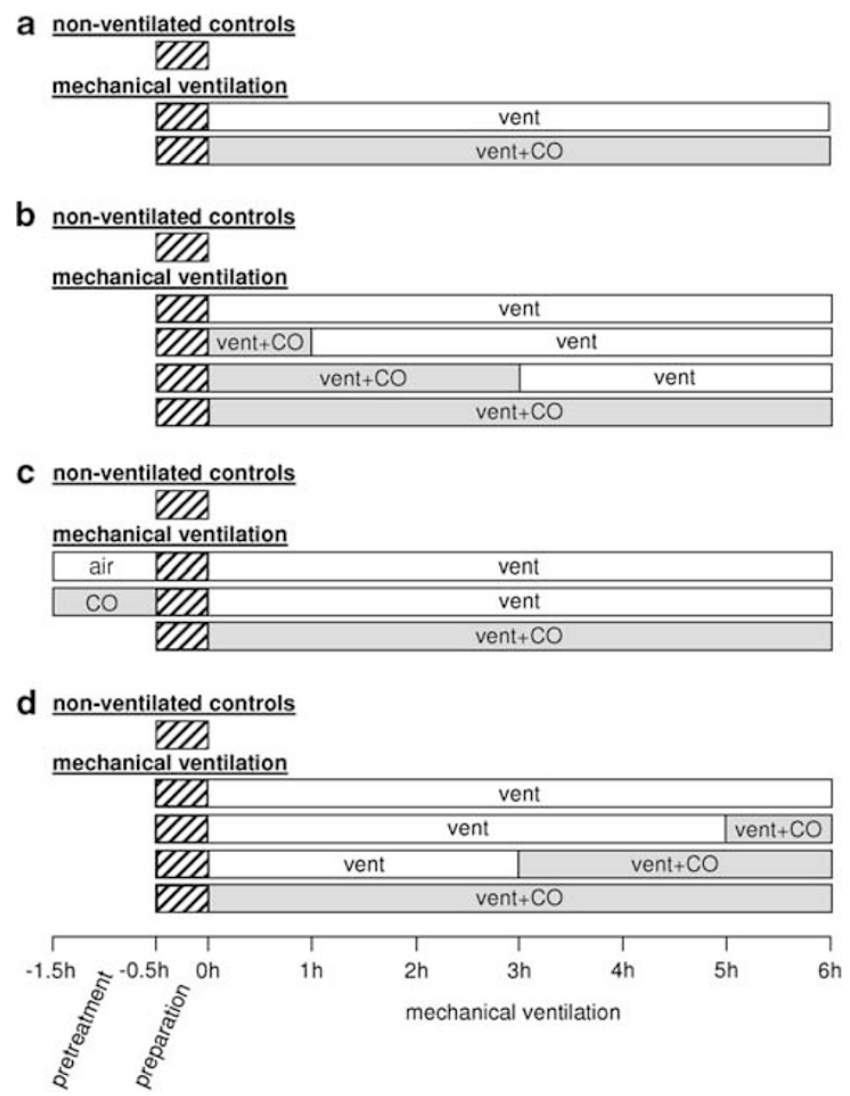

Figure 1 Experimental setting and groups. Mice were instrumented but not ventilated (control), ventilated with $12 \mathrm{ml} / \mathrm{kg}$ for $6 \mathrm{~h}$ with either synthetic air (vent) or synthetic air +250 p.p.m. carbon monoxide (vent $+\mathrm{CO})$. (a-d) The individual experimental series are depicted. The start and end of $\mathrm{CO}$ application for each series is indicated.

\section{Tissue Sampling and Bronchoalveolar Lavage}

At the end of each experiment, mice were sacrificed. Blood was withdrawn from the left carotid artery and serum samples were frozen and stored at $-80^{\circ} \mathrm{C}$. Tissue samples were snap frozen and stored at $-80^{\circ} \mathrm{C}$ for subsequent analysis. First, the left lung lobe was ligated and a bronchoalveolar lavage (BAL) was performed via the tracheal catheter in the right lung lobe using $0.8 \mathrm{ml}$ phosphate-buffered saline. The recovered volume was centrifuged and the supernatant was snap frozen and stored at $-80^{\circ} \mathrm{C}$ until further use. The pellet was re-dissolved, total cells were counted under the light microscope, and the relative amount of neutrophils was determined from methanol-fixed cytospin slides, stained with fast green, eosin and thiazine (Diff-Quick, Medion Diagnostics AG, Düdingen, Switzerland). Following the BAL, the right lobes were removed, snap frozen and kept until further use at $-80^{\circ} \mathrm{C}$. Afterwards, the left bronchus was re-opened and optimal cutting temperature compound (Tissue-Tek, Sikura Fintek $\mathrm{GmbH}$, Staufen, Germany) was mixed with phosphate-buffered saline in a 1:3 ratio, and administered with a constant pressure of $20 \mathrm{cmH} 2 \mathrm{O}$ via the tracheal catheter to unfold the lung lobe. Then, the lobe was extracted and embedded into optimal cutting temperature compound, frozen in liquid nitrogen and kept at $-80^{\circ} \mathrm{C}$ until further use.

\section{Measurements of Cytokines and Myeloperoxidase}

BAL aliquots were analyzed using IL-1 $\beta$ ELISA kits (R\&D Systems GmbH, Wiesbaden, Germany) according to the manufacturer's instructions. Serum samples were tested for both IL-1 $\beta$ and myeloperoxidase (MPO) glycoprotein (HK210 ELISA, Hycult Biotech GmbH, Beutelsbach, Germany) according to the manufacturer's instructions.

\section{Histological Examination}

Cryosections $(12 \mu \mathrm{m})$ of the left lung were subjected to hematoxylin and eosin $(\mathrm{H}+\mathrm{E})$ staining. From each lung, four representative photos were taken (magnification $\times 400$ ). Five high power fields were randomly assigned to each photo and alveolar wall thickness was analyzed by Axiovision software (AxioVS40LE, Zeiss, Jena, Germany). In each high power field, the degree of lung damage was determined by a modified VILI score: ${ }^{29}$ (a) thickness of the alveolar walls, (b) infiltration or aggregation of inflammatory cells, and (c) hemorrhage. Each item was graded in a blinded fashion according to the following five-point scale: 0: minimal damage, 1: mild damage, 2: moderate damage, 3: severe damage, 4: maximal damage. The degree of lung damage was assessed by the sum of scores ranging from 0 to 12 for each high power field. The average of the sum of each field score per lung was compared among groups.

\section{Statistical Analysis}

Graphs represent mean values + standard error of means (s.e.m.). Data were further analyzed using the one-way analysis of variance (ANOVA) followed by the StudentNewman-Keuls post hoc test. In case of two group comparisons, the Student's $t$-test or the Mann-Whitney Rank Sum test was used (Sigmastat statistical software, Synstat, Erkrath, Germany). $P<0.05$ was considered significant. In case of an unpaired Student's $t$-test or ANOVA followed by a Bonferroni-correction, $P<0.007$ was considered significant.

\section{RESULTS \\ Effect of Ventilation and $\mathrm{CO}$ on Lung Function}

Since lung function during ventilation is critical for the development of VILI, we first analyzed physiological and blood gas parameters during ventilation (Figure 2). No differences could be detected between mice ventilated with air or with $\mathrm{CO}$ for $6 \mathrm{~h}$ with respect to body temperature, blood pressure, inspiratory peak and plateau pressure, $\mathrm{pH}$, or $\mathrm{PaCO}_{2}$ (Figure 2a). Although $\mathrm{PaO}_{2}$ was alike in both groups at the start of ventilation (data not shown) and remained stable in airventilated mice, $\mathrm{PaO}_{2}$ slightly decreased in $\mathrm{CO}$-ventilated mice at the end of the ventilation period. $\mathrm{COHb}$ levels were increased in mice receiving $\mathrm{CO}$ treatment (Figure 2a). Total respiratory system compliance was slightly lower in CO-ventilated mice without reaching statistical significance (Figure $2 b$ ). 
a

\begin{tabular}{|r|rr|rr|}
\hline & \multicolumn{2}{|c|}{6 h air } & \multicolumn{2}{|c|}{$6 \mathrm{~h} \mathrm{co}$} \\
\hline $\mathrm{Tb}\left[{ }^{\circ} \mathrm{C}\right]$ & 36.3 & $( \pm 0.1)$ & 36.2 & $( \pm 0.1)$ \\
\hline $\mathrm{BP}[\mathrm{mmHg}]$ & 71 & $( \pm 4)$ & 65 & $( \pm 3)$ \\
\hline $\mathrm{P}_{\text {poak }}\left[\mathrm{cm} \mathrm{H}_{2} \mathrm{O}\right]$ & 10.0 & $( \pm 0.2)$ & 10.3 & $( \pm 0.2)$ \\
\hline $\mathrm{P}_{\text {plateau }}\left[\mathrm{cm} \mathrm{H}_{2} \mathrm{O}\right]$ & 7.5 & $( \pm 0.1)$ & 7.8 & $( \pm 0.2)$ \\
\hline $\mathrm{pH}$ & 7.261 & $( \pm 0.012)$ & 7.234 & $( \pm 0.025)$ \\
\hline $\mathrm{PaCO}_{2}[\mathrm{mmHg}]$ & 36.1 & $( \pm 2.0)$ & 39.8 & $( \pm 3.0)$ \\
\hline $\mathrm{PaO}_{2}[\mathrm{mmHg}]$ & 106.9 & $( \pm 4.9)$ & 88.0 & $( \pm 6.3)^{*}$ \\
\hline $\mathrm{COHb}^{*}[\%]$ & 5.4 & $( \pm 0.4)$ & 29.3 & $( \pm 0.5)^{*}$ \\
\hline
\end{tabular}

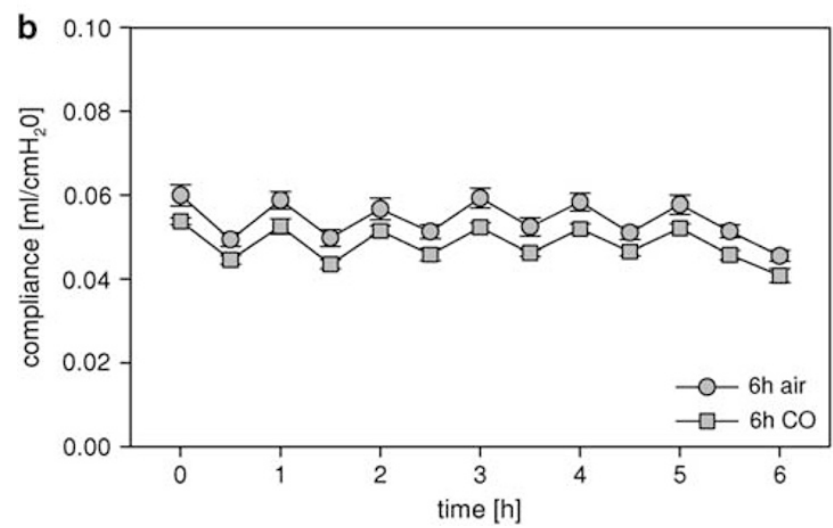

Figure 2 Effect of ventilation and carbon monoxide on lung function. Mice were ventilated with $12 \mathrm{ml} / \mathrm{kg}$ for $6 \mathrm{~h}$ with either synthetic air (air) or synthetic air +250 p.p.m. carbon monoxide (CO) as indicated. Body temperature $\left(T_{\mathrm{b}}\right)$, mean arterial blood pressure $(\mathrm{BP})$, peak airway pressure $\left(P_{\text {peak }}\right)$, and plateau airway pressure $\left(P_{\text {plateau }}\right)$ were continuously monitored and recorded every $30 \mathrm{~min}$. Blood gas analysis and $\mathrm{COHb}$ measurements were performed at the end of the experiment (a). Total respiratory compliance was calculated every $30 \mathrm{~min}$ (b). Data represent mean values \pm s.e.m. for $n=7$ /group. Student's $t$-test and Mann-Whitney Rank Sum test were used for statistical analyses, ${ }^{*} P<0.05$ vs 6 -h air.

\section{Effect of Ventilation and CO Inhalation on Lung Injury}

Next, we examined the local effects of inhaled $\mathrm{CO}$ on the development of lung injury in mechanically ventilated mice. Hematoxylin and eosin-stained sections revealed that nonventilated control mice displayed no histological signs of lung injury (Figure 3a). Ventilation with air for $6 \mathrm{~h}$ markedly increased alveolar wall thickness and cellular infiltration (Figure $3 \mathrm{~b}$ ). In contrast, the presence of CO (250 p.p.m.) during mechanical ventilation prevented lung injury (Figure 3c). Quantitative analysis of all three experimental groups showed a significant reduction of alveolar wall thickness (Figure 3d) and VILI score in CO-treated mice in comparison to air-ventilated animals (Figure 3e).

\section{Effect of Ventilation and CO Inhalation on Lung and Systemic Inflammation}

Mechanical ventilation elicits a strong pulmonary inflammation, exemplified by transmigration of inflammatory cells (eg, neutrophils), and the release of pro-inflammatory cytokines, that has an essential role in the progression of VILI. ${ }^{3,4,30,31}$ While cellular infiltration into non-ventilated lungs was minimal, mechanical ventilation markedly increased the total cell number in the BAL fluid (Figure $4 \mathrm{a}$ ), the relative number of neutrophils (Figure $4 \mathrm{~b}$ ), and IL-1 $\beta$ release (Figure $4 \mathrm{c}$ ). In contrast, the presence of $\mathrm{CO}$ during mechanical ventilation clearly reduced total cell count, neutrophil count, and IL-1 $\beta$ content in the BAL fluid as compared with mechanical ventilation with air alone. In a next step, we analyzed the effect of $\mathrm{CO}$ inhalation on systemic pro-inflammatory factors. The MPO glycoprotein is known to be released from activated neutrophils (eg, during lung injury in mechanical ventilation). ${ }^{32-34}$ In our setting, mechanical ventilation clearly increased MPO in serum (Figure 4d). However, CO treatment had no effect on MPO levels. We also analyzed the release of the pro-inflammatory cytokine IL- $1 \beta$, revealing that neither mechanical ventilation nor $\mathrm{CO}$ inhalation had an impact on systemic IL- $1 \beta$ release (Figure 4e).

\section{Time-Dependent Effect of CO Application on Lung Function}

No differences were detected between groups regarding body temperature, blood pressure, inspiratory peak pressure, plateau pressure, or $\mathrm{pH}$ (Supplementary Figure $1 \mathrm{~A}$ ). $\mathrm{PaCO}_{2}$ was increased in mice treated with $\mathrm{CO}$ in the first hour of ventilation. $\mathrm{PaO}_{2}$ values at the end of the experiment were lower in animals that were subjected to $\mathrm{CO}$ for $1 \mathrm{~h}$ or for $6 \mathrm{~h}$. $\mathrm{COHb}$ levels were highest in mice receiving $6 \mathrm{~h}$ CO treatment (Supplementary Figure 1A). Total respiratory system compliance did not differ among groups (Supplementary Figure 1B).

Time-Dependent Effect of CO Application on Lung Injury To determine the relationship between $\mathrm{CO}$ exposure time and lung protective effects, $\mathrm{CO}$ administration was initiated with the onset of mechanical ventilation, but time dependently discontinued. In contrast to non-ventilated control mice (Figure 5a), ventilation with air led to an increase in alveolar wall thickness and cellular infiltration (Figure 5b). Ventilation with $\mathrm{CO}$ for $1 \mathrm{~h}$, followed by 5 -h air ventilation, also decreased both histological signs of lung injury (Figure 5c). Surprisingly, ventilation with $\mathrm{CO}$ for $3 \mathrm{~h}$ and interruption of $\mathrm{CO}$ supplementation for the following $3 \mathrm{~h}$, showed no impact on lung damage as compared with air ventilation alone (Figure 5d). Finally, ventilation with $\mathrm{CO}$ for $6 \mathrm{~h}$ without discontinuation led to a reduction of alveolar wall thickness and cellular infiltration comparable to 1-h CO exposure (Figure 5e). Quantification of alveolar wall thickness (Figure 5f) and assessment of the VILI score (Figure $5 \mathrm{~g}$ ) for all experimental groups confirmed that exposure to $\mathrm{CO}$ for $1 \mathrm{~h}$ as well as for $6 \mathrm{~h}$ led to an almost identical reduction in ventilation-mediated lung injury.

\section{Time-Dependent Effect of CO Application on Lung Inflammation}

In order to determine the time-dependent effects of $\mathrm{CO}$ inhalation on the inflammatory response to mechanical 

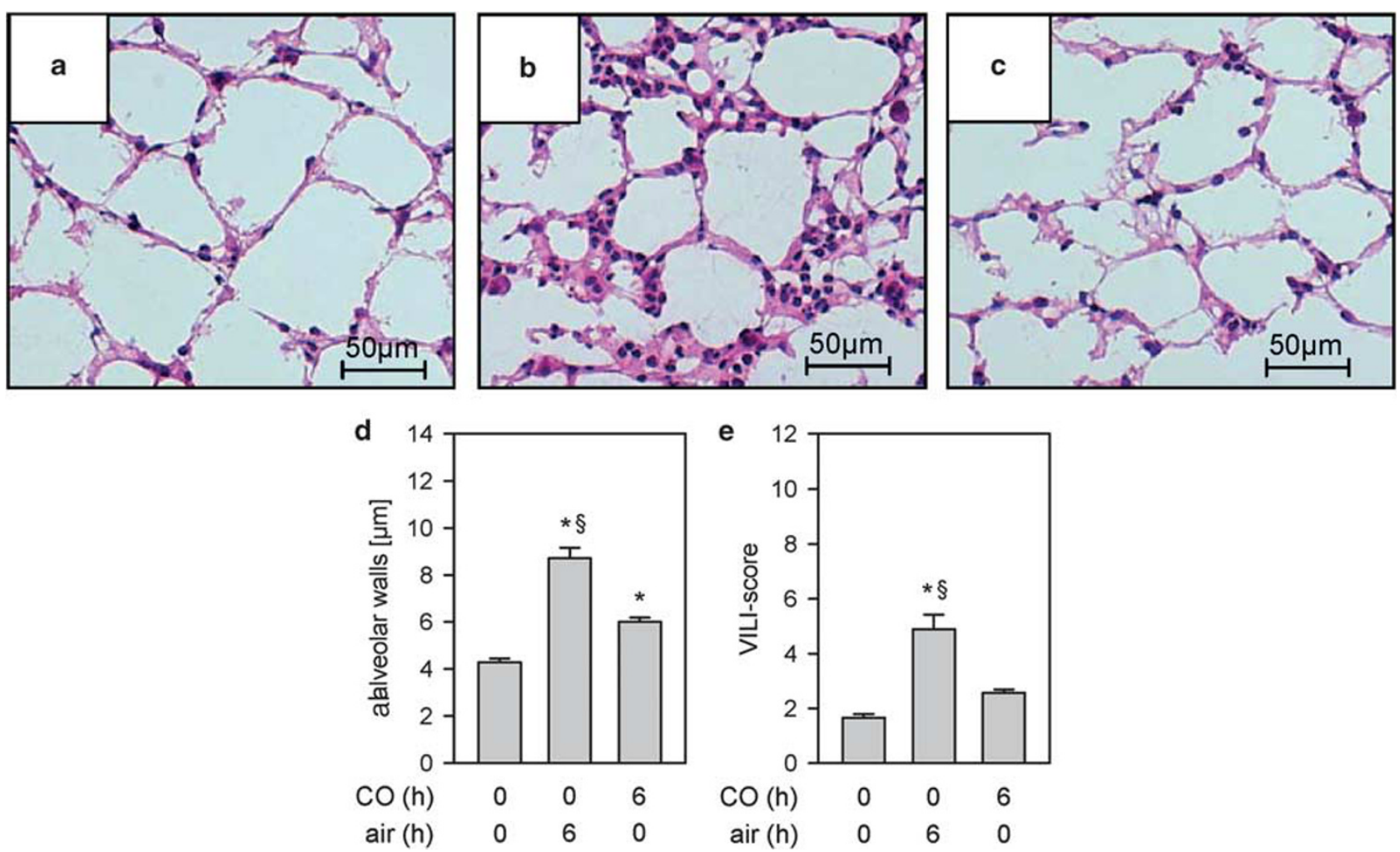

Figure 3 Effect of ventilation and carbon monoxide treatment on lung injury. As controls, mice were allowed to spontaneously breathe air (a), or were ventilated with $12 \mathrm{ml} / \mathrm{kg}$ for $6 \mathrm{~h}$ with either synthetic air (b) or synthetic air +250 p.p.m. carbon monoxide (CO) (c). Sections from the left lung lobe were stained by hematoxylin and eosin. Representative pictures are shown for each experimental group (magnification $=\times 400$, a-c). High power fields were randomly assigned to measure alveolar wall thickness (d) and ventilator-induced lung injury (VILI) score (e). Data represent mean values \pm s.e.m. for $n=7 /$ group. ANOVA (Student-Newman-Keuls post hoc test), ${ }^{\star} P<0.05$ vs control, ${ }^{\$} P<0.05$ vs 6 -h CO-ventilated group.

ventilation, we analyzed total cell count, neutrophil infiltration, and IL-1 $\beta$ release in the BAL fluid (Figure 6). Total cell counts of non-ventilated mice were minimal, whereas ventilation with air alone increased total cell counts (Figure 6a). The presence of CO (250 p.p.m.) for 1, 3, or $6 \mathrm{~h}$ reduced the number of infiltrating total cells. Regarding neutrophil cell infiltration, relative neutrophil counts were negligible in nonventilated mice, whereas air ventilation led to a substantial elevation in neutrophil counts (Figure 6b). Both 1 and $6 \mathrm{~h}$ of $\mathrm{CO}$ treatment inhibited neutrophil influx. However, 3-h CO followed by 3 -h air ventilation was insufficient to prevent neutrophil migration into the BAL fluid. The release of the cytokine IL- $1 \beta$ was increased by air ventilation but inhibited by all other treatments, regardless of whether $\mathrm{CO}$ was applied for 1,3 , or $6 \mathrm{~h}$ (Figure 6c).

\section{Effect of Pre-Treatment with CO on Lung Function}

Body temperature, blood pressure, inspiratory peak pressure, and plateau pressure did not differ among groups (Supplementary Figure $2 \mathrm{~A}$ ). $\mathrm{pH}$ was slightly reduced in pre-treated mice, while $\mathrm{PaCO}_{2}$ was increased, and $\mathrm{PaO}_{2}$ was decreased in mice treated with $\mathrm{CO}$ at the end of ventilation. $\mathrm{COHb}$ levels were highest in mice receiving $6 \mathrm{~h} \mathrm{CO}$ treatment
(Supplementary Figure 2A). Total respiratory system compliance did not differ among groups (Supplementary Figure 2B).

\section{Effect of Pre-Treatment with CO on Lung Injury}

Pre-treatment with $\mathrm{CO}$ has been previously shown to confer protective effects in several in vivo and in vitro models. ${ }^{20,35-40}$ Especially, the administration of 250 p.p.m. CO for $1 \mathrm{~h}$ before the onset of the deleterious treatment proved to exert beneficial effects. ${ }^{36,41-43}$ Therefore, we subjected mice to breathe 250 p.p.m. CO spontaneously for $1 \mathrm{~h}$ before instrumentation and mechanical ventilation for the following $6 \mathrm{~h}$ in the absence of CO. Representative histological slides in Figure 7 show normal lung architecture in non-ventilated control mice (Figure 7a) and lung damage in mice ventilated with air for $6 \mathrm{~h}$, characterized by increased thickness of alveolar septa and cellular infiltration (Figure $7 b$ ). One hour of spontaneous inhalation of CO (250 p.p.m.) before mechanical ventilation had no impact on lung injury (Figure $7 \mathrm{c}$ ). As an internal control group, ventilation with $\mathrm{CO}$ for $6 \mathrm{~h}$ without pre-treatment clearly reduced lung injury (Figure 7d). Quantification of alveolar thickness (Figure 7e) and VILI score (Figure 7f) confirmed the lack of lung protection when mice were pre-treated for $1 \mathrm{~h}$ with CO inhalation. 

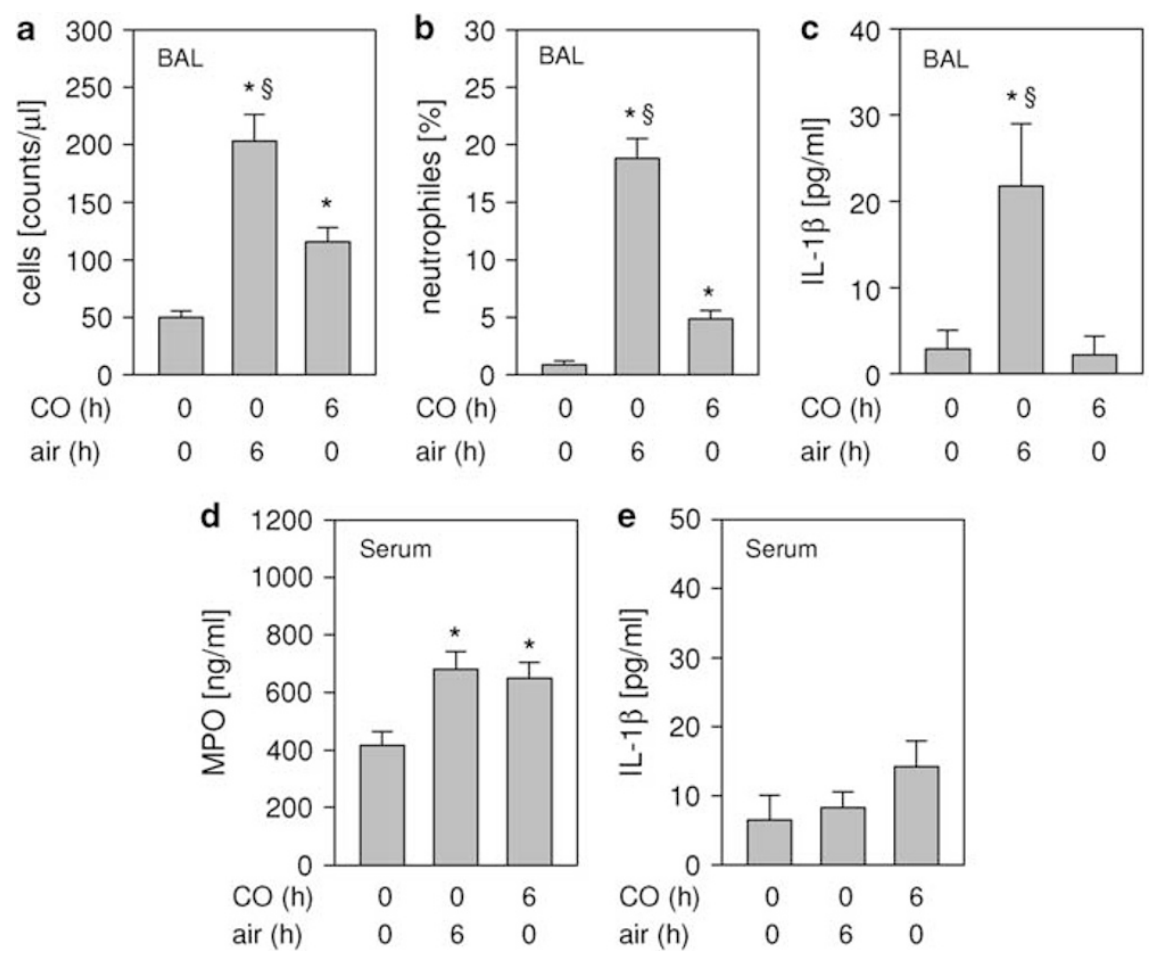

Figure 4 Effect of ventilation and carbon monoxide treatment on lung inflammation. As controls, mice were allowed to spontaneously breathe air, or were ventilated with $12 \mathrm{ml} / \mathrm{kg}$ for $6 \mathrm{~h}$ with either synthetic air or synthetic air +250 p.p.m. carbon monoxide (CO). Bronchoalveolar lavage was performed in the right lung. Total cells were counted under a light microscope (a) and the relative amount of neutrophils (b) was determined by cytospin analysis. Interleukin-1 $\beta$ (IL-1 $\beta$ ) contents were quantified by ELISA (c). Myeloperoxidase (MPO; d) and IL-1 $\beta$ (e) release was determined in serum samples by ELISA. Graphs represent mean values \pm s.e.m., $n=7 /$ group. ANOVA (Student-Newman-Keuls post hoc test), ${ }^{\star} P<0.05$ vs control, ${ }^{\S} P<0.05$ vs 6 -h CO-ventilated group.

Effect of Pre-Treatment with CO on Lung Inflammation Similar results were obtained with respect to the effects of $\mathrm{CO}$ pre-treatment on the inflammatory response. While mechanical ventilation alone increased cell count (Figure 8a), neutrophil count (Figure $8 \mathrm{~b}$ ), and IL-1 $\beta$ release (Figure $8 \mathrm{c}$ ), no alterations in these parameters were observed with $1 \mathrm{~h}$ $\mathrm{CO}$ pre-treatment. In contrast, $\mathrm{CO}$ administration over $6 \mathrm{~h}$ reduced the inflammatory response as described above.

\section{Effect of Delayed CO Treatment on Lung Function}

There were no differences detectable between groups concerning body temperature, blood pressure, inspiratory peak pressure, plateau pressure, $\mathrm{pH}$, or $\mathrm{PaCO}_{2}$ (Supplementary Figure $3 \mathrm{~A}) . \mathrm{PaO}_{2}$ was slightly decreased in the 3-h air followed by 3-h CO-treated group at the end of ventilation. $\mathrm{COHb}$ levels were high in all groups receiving $\mathrm{CO}$ treatment (Supplementary Figure 3A). Total respiratory system compliance differed at two time points among groups (Supplementary Figure 3B).

\section{Effect of Delayed CO Treatment on Lung Injury}

The effects of delayed CO administration on VILI were evaluated (Figure 9). As compared with control animals (Figure 9a), ventilation with air alone for $6 \mathrm{~h}$ clearly induced alveolar wall thickening and cellular infiltration as signs of lung injury (Figure $9 \mathrm{~b}$ ). The onset of $\mathrm{CO}$ application after $5 \mathrm{~h}$ of air ventilation failed to alter lung injury (Figure 9c). In contrast, administration of $\mathrm{CO}$ after $3 \mathrm{~h}$ of air ventilation reduced alveolar thickness (Figure 9d). The effect was even more pronounced if $\mathrm{CO}$ was administered at the start of mechanical ventilation (Figure 9e). Quantitative analysis of alveolar wall thickness (Figure 9f) as well as analysis of VILI score (Figure 9g) confirmed these results. Extension of total experimental time and extension of the ventilation period (Supplementary Figure 4) provided protective effects by $\mathrm{CO}$ application, even when CO was administered as late as $5 \mathrm{~h}$ after the onset of mechanical ventilation. This was true for 5-h air/3-h CO as compared with the time-matched air ventilation, and to a lesser extent in the 5-h air/5-h CO group (Supplementary Figure 5A-E). Although we only tested two animals per group, a trend towards reduction of lung damage as assessed by the means of decreased alveolar wall thickening and VILI score (data not shown) became evident for both time points (5-h air/3-h CO and 5-h air/5-h CO), when quantitatively analyzing the cryosections.

\section{Effect of Delayed Treatment with CO on Lung Inflammation}

With respect to the inflammatory response, total cell counts in BAL fluid (Figure 10a), neutrophil infiltration 

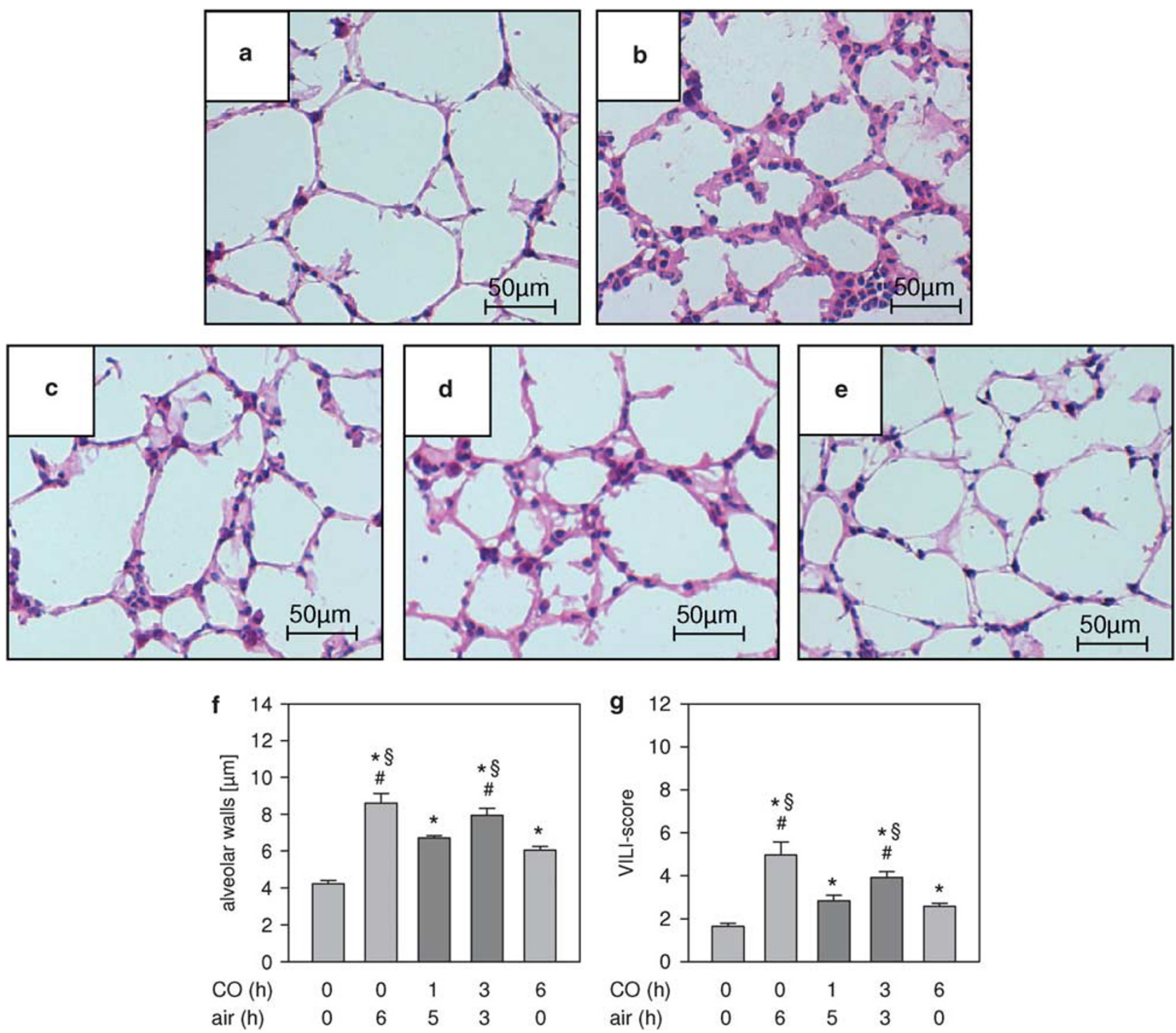

Figure 5 Effect of minimizing carbon monoxide treatment on lung injury. As controls, mice were allowed to spontaneously breathe air (a), or were ventilated with $12 \mathrm{ml} / \mathrm{kg}$ for $6 \mathrm{~h}$ with synthetic air (b). Additionally, 250 p.p.m. carbon monoxide (CO) was applied for 1 (c), 3 (d), or $6 \mathrm{~h}$ (e), followed by ventilation with air alone for the remaining 5,3 , or $0 \mathrm{~h}$ of the experiment, as indicated. Sections from the left lung lobe were stained with hematoxylin and eosin. Representative pictures are shown for each experimental group (magnification $=\times 400$, a-e). High power fields were randomly assigned to measure alveolar wall thickness (f) and ventilator-induced lung injury (VILI) score (g). Data represent mean values \pm s.e.m. for $n=6 /$ group. ANOVA (StudentNewman-Keuls post hoc test), ${ }^{*} P<0.05$ vs control, ${ }^{\circledR} P<0.05$ vs 6 -h CO-ventilated group, ${ }^{\#} P<0.05$ vs 1 -h CO and 5 -h air-ventilated group.

(Figure 10b), and IL-1 $\beta$ content (Figure 10c) were increased in air-ventilated mice. Surprisingly, delaying $\mathrm{CO}$ administration (250 p.p.m.) for $5 \mathrm{~h}$ and $3 \mathrm{~h}$ from the initiation of mechanical ventilation still significantly reduced the inflammatory response. However, the continuous presence of $\mathrm{CO}$ for the entire ventilation interval afforded the most pronounced reduction of inflammatory parameters. Interestingly, the delayed start of $\mathrm{CO}$ treatment and the simultaneous extension of mechanical ventilation decreased neutrophils and IL- $1 \beta$ release in the $5-\mathrm{h}$ air/3-h CO group. However, there was only a trend towards reduction of IL- $1 \beta$ in 5-h air/5-h CO mice and we did not observe an effect on neutrophils when mice were ventilated for $10 \mathrm{~h}$ in the presence or absence of CO (data not shown).

\section{DISCUSSION}

Despite the fact that mechanical ventilation represents a lifesaving tool in emergency and critical care medicine, cyclic stretching of the lung caused by mechanical ventilation may lead to VILI. ${ }^{2}$ We and others ${ }^{25-27}$ have previously described that application of CO can substantially prevent the development of VILI during mechanical ventilation. However, the kinetics of the protective effects of $\mathrm{CO}$ remain incompletely described. For example, it remains unclear for how long CO 

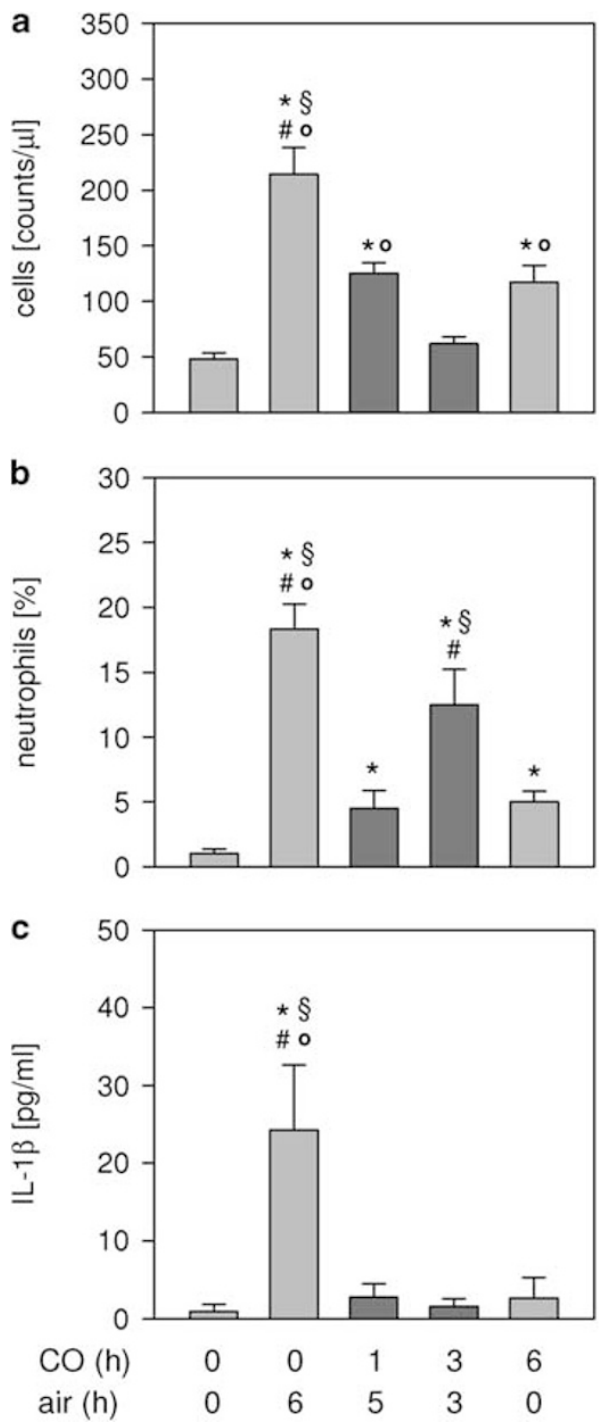

Figure 6 Effect of minimizing carbon monoxide treatment on lung inflammation. As controls, mice were allowed to spontaneously breathe air, or were ventilated with $12 \mathrm{ml} / \mathrm{kg}$ for $6 \mathrm{~h}$ with synthetic air. Additionally, 250 p.p.m. carbon monoxide (CO) was applied for 1, 3, or $6 \mathrm{~h}$, followed by ventilation with air alone for the remaining 5,3 , or $0 \mathrm{~h}$ of the experiment, as indicated. Bronchoalveolar lavage was performed in the right lung. Total cells were counted under a light microscope (a). The relative amount of neutrophils was determined by cytospin analysis (b). Interleukin-1 $\beta$ (IL-1 $\beta$ ) contents were quantified by ELISA (c). Graphs represent mean values \pm s.e.m., $n=6 /$ group. ANOVA (Student-Newman-Keuls post hoc test), ${ }^{\star} P<0.05$ vs control, ${ }^{\$} P<0.05$ vs 6 -h CO-ventilated group, ${ }^{\#} P<0.05$ vs 1 -h $\mathrm{CO}$ and 5 -h air-ventilated group, ${ }^{\circ} P<0.05$ vs 3-h $\mathrm{CO}$ and 3 -h air-ventilated group.

must be applied, or for how long the application of $\mathrm{CO}$ can be delayed in order to achieve the observed therapeutic effects. Therefore, the present study aimed to rigorously define the time dependence of the protective effects of $\mathrm{CO}$ treatment. According to the present results, we report that $\mathrm{CO}$ inhalation prevents VILI. Importantly, CO inhalation for as little as $1 \mathrm{~h}$ was sufficient for a sustained protective effect. Exclusive pre-treatment with $\mathrm{CO}$ demonstrated no impact on the development of VILI. Finally, the delayed administration of $\mathrm{CO}$ (ie, up to $3 \mathrm{~h}$ after the onset of mechanical ventilation) still conferred protection against VILI.

A ventilation mode using $12 \mathrm{ml} / \mathrm{kg}$ was chosen in order to evoke a moderate degree of lung injury and inflammatory responses comparable to what we have previously described. ${ }^{26,27}$ In our setting and as recently demonstrated, ${ }^{26,27}$ inhalation of CO (250 p.p.m.) does not alter or worsen blood gas or lung function parameters. The observed slight decrease of $\mathrm{PaO}_{2}$ and in some cases an elevated $\mathrm{PaCO}_{2}$ in CO-ventilated mice at the end of the experiment appears not to have any deleterious effect on lung function and protection against VILI. $\mathrm{PaO}_{2}$ in all groups analyzed are within physiological ranges for mice. Neither hyperoxemia nor hypoxemia was detected at any time point in the present experimental setting. This is in line with a previous study of our group applying the same experimental setting. ${ }^{27}$ Moreover, lower $\mathrm{PaO}_{2}$ values in $\mathrm{CO}$-ventilated animals might result from interaction between oxygen and CO. However, and as depicted in the Supplementary Figures, $\mathrm{PaO}_{2}$ values were variable in $\mathrm{CO}$ groups independent of the duration of $\mathrm{CO}$ application and independent of the observed protective effects. Also in agreement with previous reports, administration of $\mathrm{CO}$ prevented the development of VILI with respect to observed reduction in alveolar wall thickening, VILI score, total cellular influx, neutrophil transmigration, and cytokine release. With respect to pro-inflammatory cytokine release, we could demonstrate that $\mathrm{CO}$ inhalation exerts local rather than systemic effects. Emerging questions include for how long and for what time interval from the onset of injury must $\mathrm{CO}$ be administered in order to exert maximal protective effects. Both matters are of major clinical importance, if treatment options with low-dose $\mathrm{CO}$ are to be implemented into clinical practice in the future. First, if shorter exposures have the same effect as longer exposure times, the toxic side effects of $\mathrm{CO}$ treatment may be minimized. Second, if pre-treatment with $\mathrm{CO}$ would exert protective effects, procedures at risk for the development of ALI (eg, cardiopulmonary bypass or transplantation) could be considered for preparatory CO inhalation. Third, if delayed $\mathrm{CO}$ treatment would affect lung injury, $\mathrm{CO}$ could be considered as a potential therapeutic to be applied after lung injury has been diagnosed.

Regarding the first aspect of the study, we speculated that CO may confer protection against VILI even if the duration of application was minimized. This idea is underscored by one other study on acute pulmonary sepsis induced by intratracheal instillation of hydrochloric acid. ${ }^{19}$ While inhalation of 500 p.p.m. CO immediately after instillation for $6 \mathrm{~h}$ substantially decreased neutrophil influx and severe lung damage, as well as the upregulation of the adhesion receptor CD11b on blood neutrophils after 6 and $24 \mathrm{~h}$, continuous application of $\mathrm{CO}$ for $24 \mathrm{~h}$ could not prevent lung injury. The notion that $\mathrm{CO}$ preferentially modulates the initiation of inflammatory cascades and the early development of lung injury is clearly supported by our data. $\mathrm{CO}$ inhalation at the 

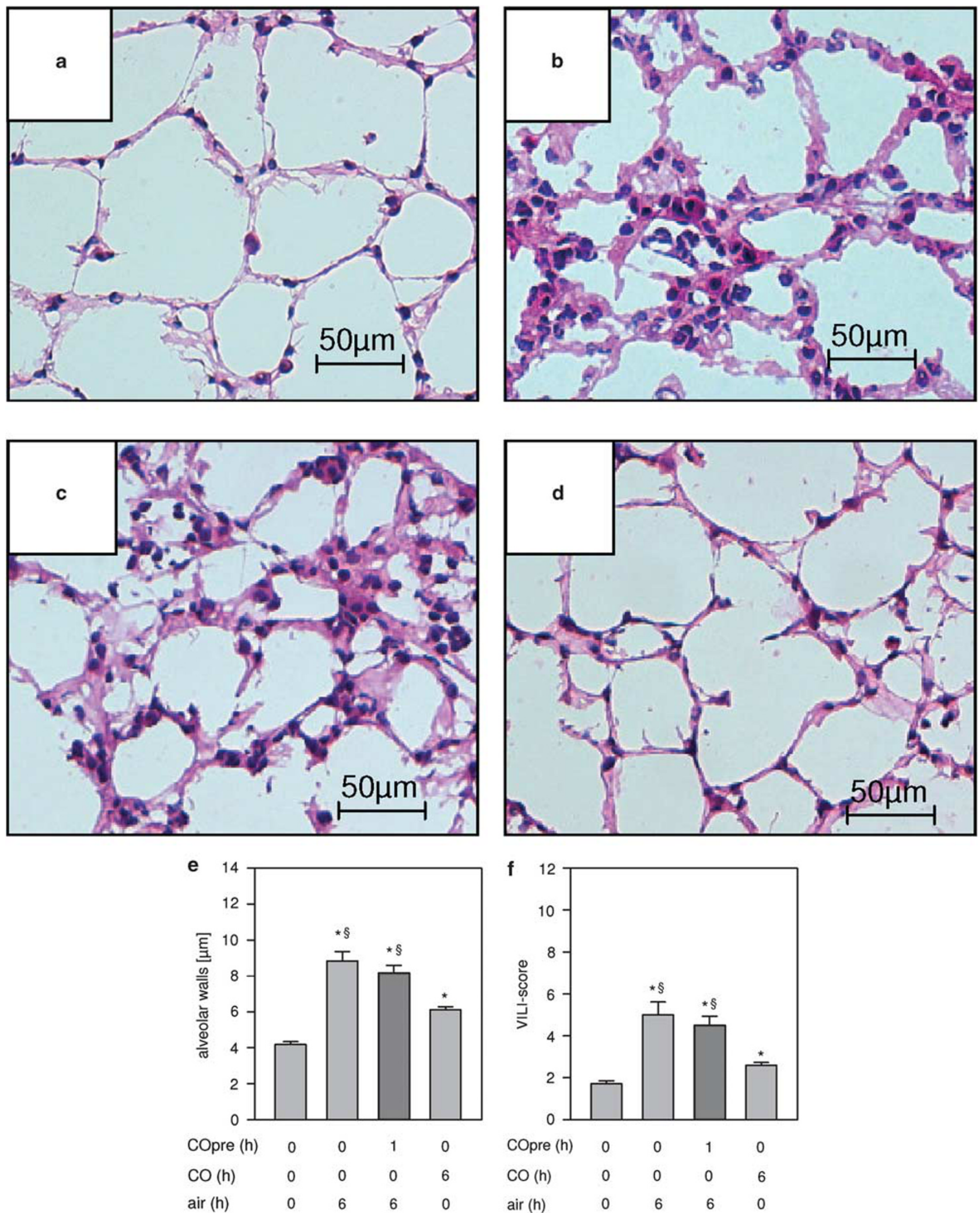

Figure 7 Effect of pre-treatment with carbon monoxide on lung injury. As controls, mice were allowed to spontaneously breathe air (a), or were ventilated with $12 \mathrm{ml} / \mathrm{kg}$ for $6 \mathrm{~h}$ with either synthetic air (b, c) or synthetic air (air) +250 p.p.m. carbon monoxide (CO) (d). In addition, mice were allowed to spontaneously breathe air (b) or 250 p.p.m. CO (c) for $1 \mathrm{~h}$ before 6-h ventilation with air. Sections from the left lung lobe were hematoxylin and eosin stained. Representative pictures are shown for each experimental group (magnification $=\times 400$, a-d). High power fields were randomly assigned to measure alveolar wall thickness (e) and ventilator-induced lung injury (VILI) score (f). Graphs represent mean values \pm s.e.m., $n=6 / g$ roup. ANOVA (Student-NewmanKeuls post hoc test), ${ }^{\star} P<0.05$ vs control, ${ }^{\circledR} P<0.05$ vs 6-h CO-ventilated group. 
onset of mechanical ventilation limited to the first hour reduced inflammatory cell influx, pro-inflammatory cytokine release, as well as alveolar wall thickening and VILI score to a similar extent compared with continuous $6 \mathrm{~h}$ CO application. Thus, the first hour during mechanical ventilation seems to have an important role in the initiation of inflammation where $\mathrm{CO}$ treatment can provide protection. In this regard, we recently reported that mechanical ventilation can upregulate Egr-1 within the first hour of treatment. ${ }^{26}$ The essential role of this pro-inflammatory protein in the development of VILI has been further shown by the fact that Egr-1 knockout mice were resistant to VILI during mechanical ventilation, and that $\mathrm{CO}$ exerted lung protective effects via modulation of the Egr-1 pathway. ${ }^{26}$ Surprisingly and in contrast to the 1-h as well as to the 6-h group, $\mathrm{CO}$ application for $3 \mathrm{~h}$, followed by $3 \mathrm{~h}$ air ventilation had no impact on the development of lung injury. Two potential explanations might apply: First, depending on time and concentration of $\mathrm{CO}$ application as well as depending on the subject's condition, $\mathrm{CO}$ might exert beneficial as well as deleterious effects. Therefore, it might be reasonable that $3 \mathrm{~h}$ $\mathrm{CO}$ inhalation leads to some latent injury as compared with $1 \mathrm{~h}$ of application. In this case, a recovery by further and continuous administration of $\mathrm{CO}$-acting as an antiinflammatory agent as in the 6-h group-would be absent. Second, it is possible that the discrepant data are due to experimental variability. Cell counts as well as IL- $1 \beta$ were not increased in the 3-h $\mathrm{CO} / 3$-h air group, supporting the assumption that despite clear anti-inflammatory patterns in this group, the absence of lung protection results from experimental variability.

As the second aim of this study, we investigated whether $\mathrm{CO}$ application before mechanical ventilation might exert protective effects in the lung. Pre-treatment or 'preconditioning' with $\mathrm{CO}$ has been studied extensively over the last few years. Analogous to ischemic or anesthetic preconditioning, ${ }^{44-46}$ inhalation of $\mathrm{CO}$ before injurious events elicited substantial protective effects in different models and organs including the lung, kidney, heart, liver, and others. ${ }^{14,16,20,35-39,47,48}$ Mechanistically, CO confers protection during ischemia/reperfusion by limiting the proinflammatory and fibrinolytic response, through the modulation of several signal transduction pathways (eg, MAPKs, heat shock proteins, Egr-1, etc.). ${ }^{16,36,37}$ In contrast to these studies, our results indicate that inhalation of $\mathrm{CO}$ before mechanical ventilation limits neither the resulting lung injury nor the inflammatory response. In light of the above studies, our findings are surprising and support the notion that preconditioning effects of $\mathrm{CO}$ are specific to the organ and/or the injury model employed. Furthermore, pre-treatment with $\mathrm{CO}$ may be effective for ischemia-reperfusion injury by specifically limiting the respiratory burst and the production of reactive oxygen species. ${ }^{14,16,36,37,39,40,47}$ However, we speculate that the development of VILI by ventilation associated with mechanical stretch, is based on a different
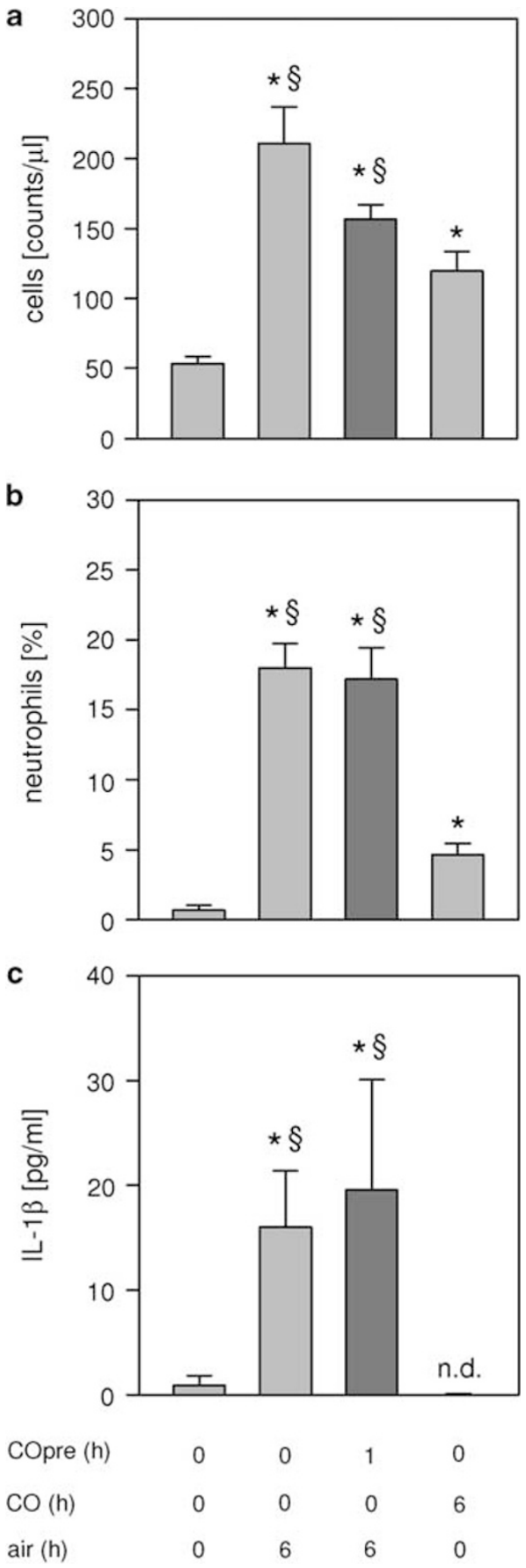

Figure 8 Effect of pre-treatment with carbon monoxide on lung inflammation. As controls, mice were allowed to spontaneously breathe air, or were ventilated with $12 \mathrm{ml} / \mathrm{kg}$ for $6 \mathrm{~h}$ with either synthetic air or synthetic air +250 p.p.m. carbon monoxide (CO) as indicated. In addition, mice were allowed to spontaneously breathe air or 250 p.p.m. CO (COpre) for $1 \mathrm{~h}$ before 6 -h ventilation with air. Bronchoalveolar lavage was performed in the right lung. Total cell counts were determined under the light microscope (a). The relative amount of neutrophils was determined by cytospin analysis (b). Interleukin-1 $\beta$ (IL-1 $\beta$ ) contents were quantified by ELISA (c). Graphs represent mean values \pm s.e.m., $n=6 /$ group. ANOVA (Student-Newman-Keuls post hoc test),

${ }^{\star} P<0.05$ vs control, ${ }^{\circledR} P<0.05$ vs 6 -h CO-ventilated group; n.d., not detectable. 

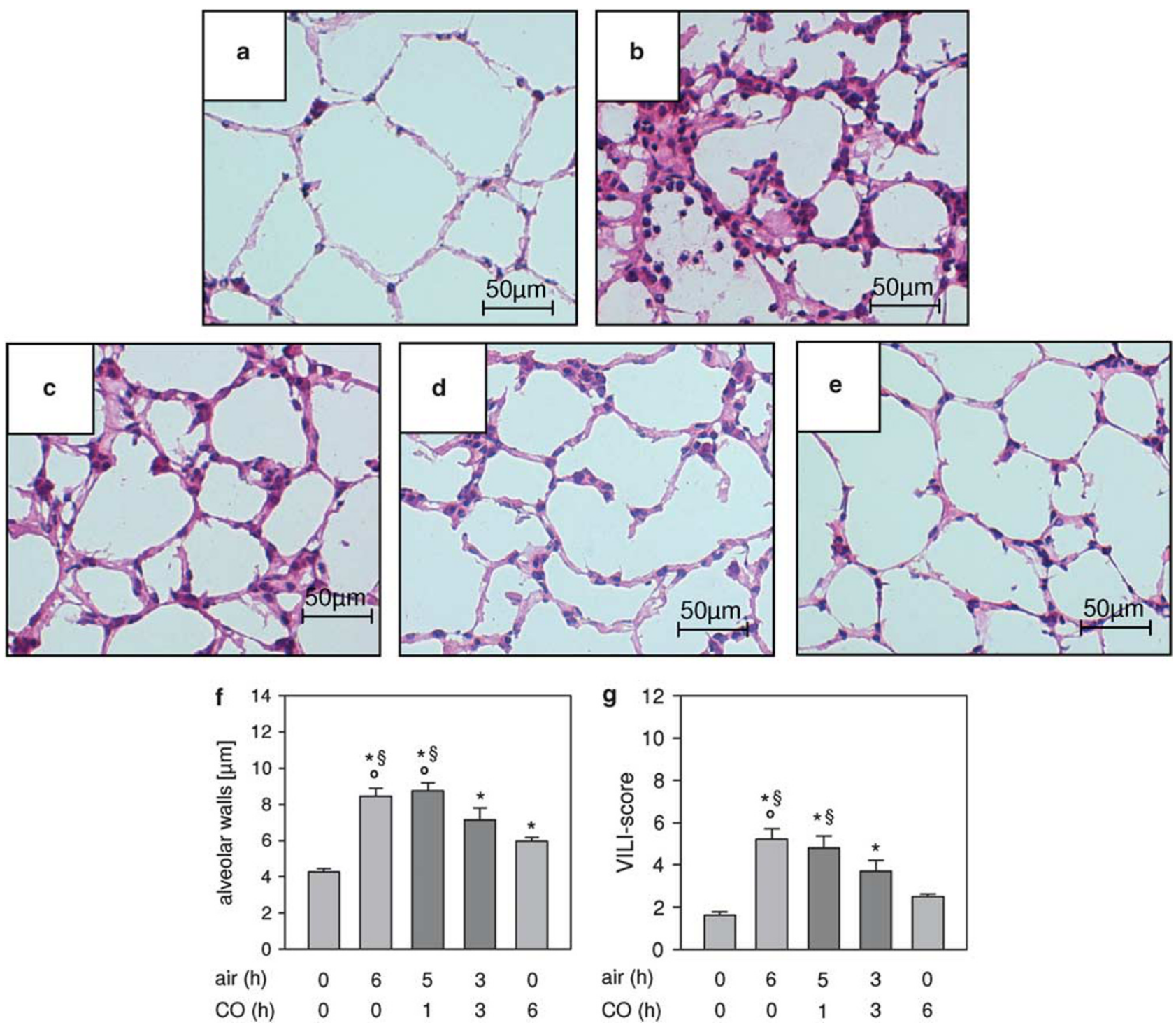

Figure 9 Effect of therapeutic treatment with carbon monoxide treatment on lung injury. As controls, mice were allowed to spontaneously breathe air (a), or were ventilated with $12 \mathrm{ml} / \mathrm{kg}$ for $6 \mathrm{~h}$ with synthetic air (b). In addition, mice were ventilated with air for $5 \mathrm{~h} \mathrm{(c),} 3 \mathrm{~h} \mathrm{(d),} \mathrm{or} 0 \mathrm{~h}(\mathbf{e})$, followed by ventilation with 250 p.p.m. carbon monoxide (CO) for 1, 3, or $6 \mathrm{~h}$ as indicated. Sections from the left lung lobe were hematoxylin and eosin stained. Representative pictures are shown for each experimental group (magnification $=\times 400$, a-e). High power fields were randomly assigned to measure alveolar wall thickness (f) and ventilator-induced lung injury (VILI) score (g). Graphs represent mean values \pm s.e.m., $n=6 / g r o u p$. ANOVA (Student-Newman-Keuls post hoc test), ${ }^{\star} P<0.05$ vs control, ${ }^{\circledR} P<0.05$ vs 6 -h CO-ventilated group, ${ }^{\circ} P<0.05$ vs 3 -h air 3 -h CO-ventilated group.

pathological mechanism, that is apparently not affected by $\mathrm{CO}$ pre-treatment. Therefore, and with respect to the positive results obtained by minimizing $\mathrm{CO}$ application during ventilation, it appears to be important to administer CO simultaneously rather than before mechanical ventilation.

Finally, we intended to define whether delayed CO application during mechanical ventilation could exert therapeutic effects. Interestingly, only a very limited number of studies have focused on the therapeutic potential of CO application in terms of organ protection when $\mathrm{CO}$ is applied after the insult has been set. As mentioned above, lessons might be learned from ischemia-reperfusion models that consist of two subsequent injurious events (ie, ischemia followed by reperfusion). Ischemia itself leads to cellular dysfunction and injury. ${ }^{49-51}$ The application of the CORM-3 after the ischemic period and with the onset of reperfusion substantially reduced heart infarct size in mice. ${ }^{52}$ Likewise, inhalation of 125 or 250 p.p.m. CO with the onset of reperfusion inhibited edema formation and infarct volume in a mouse cerebral occlusion model. ${ }^{53} \mathrm{CO}$-mediated protection appears not to be restricted to local effects. As demonstrated in remote limb ischemiareperfusion models, exposure of animals to 250 p.p.m. CO or to CORMs at the time of reperfusion reduced the intestinal and pulmonary inflammatory response. ${ }^{54,55}$ However, it is 

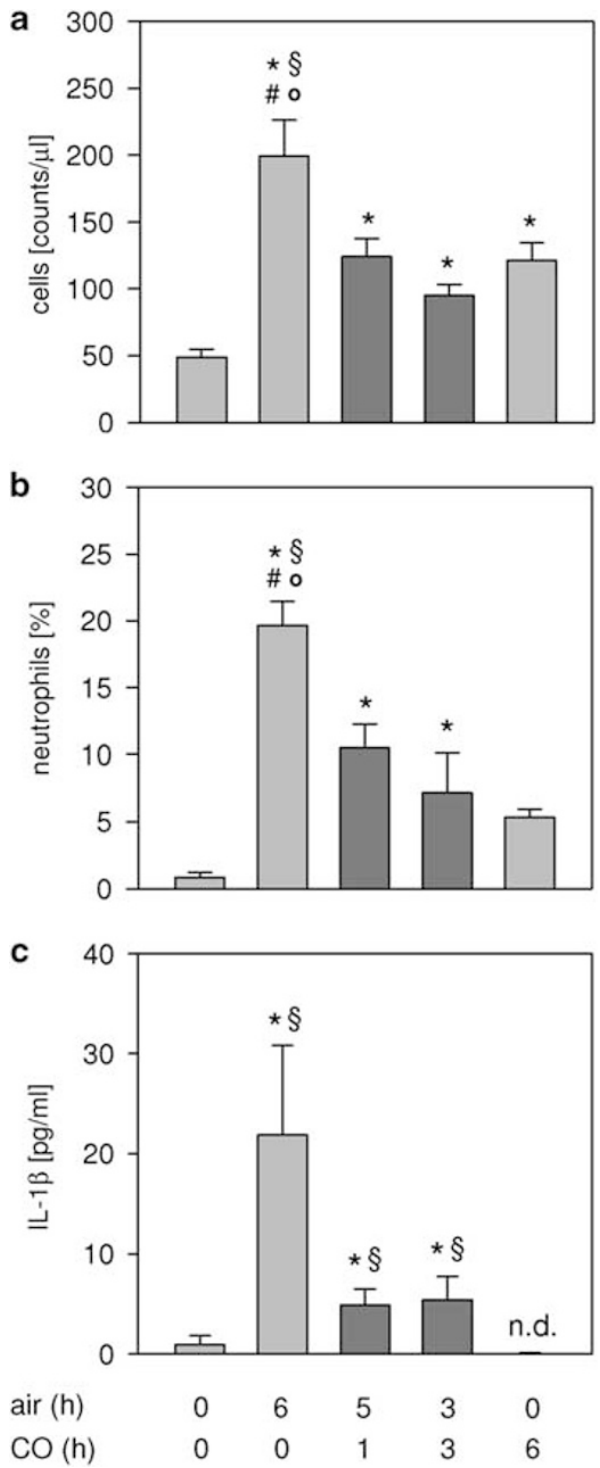

Figure 10 Effect of therapeutic treatment with carbon monoxide treatment on lung inflammation. As controls, mice were allowed to spontaneously breathe air or were ventilated with $12 \mathrm{ml} / \mathrm{kg}$ for $6 \mathrm{~h}$ with synthetic air. In addition, mice were ventilated with air for 5, 3, or $0 \mathrm{~h}$, followed by ventilation with 250 p.p.m. CO for 1, 3, or $6 \mathrm{~h}$ as indicated. Bronchoalveolar lavage was performed in the right lung. Total cell counts were determined under the light microscope (a). The relative amount of neutrophils was determined by cytospin analysis (b). Interleukin-1 $\beta$ (IL-1 $\beta$ ) contents were quantified by ELISA (c). Graphs represent mean values \pm s.e.m., $n=6 /$ group. ANOVA (Student-Newman-Keuls post hoc test), ${ }^{*} P<0.05$ vs control, ${ }^{\circledR} P<0.05$ vs 6 -h CO-ventilated group, ${ }^{\#} P<0.05$ vs 5 -h air 1 -h CO-ventilated group, ${ }^{\circ} P<0.05$ vs 3 -h air 3 -h CO-ventilated group; n.d., not detectable.

well known that reperfusion represents the most important event for ischemia-reperfusion injury, and therefore, application of $\mathrm{CO}$ at the beginning of reperfusion cannot be considered as a post-treatment relative to ischemia. Two reports investigated post-treatment with $\mathrm{CO}$ in models closer to the clinical situation in which the injurious event occurs before a therapeutic strategy can be initiated. One hour after lipopolysaccharide instillation, Liu et $a l^{56}$ treated rats with 250 p.p.m. CO and demonstrated that the resulting intestinal injury was prevented. The authors found upregulation of $\mathrm{p} 38$ MAPK, reduced neutrophil activity, and decreased expression of intracellular adhesion molecule-1, indicating that CO limited inflammation even when the application was postponed. ${ }^{56}$ In another study, Tsui et al ${ }^{57}$ induced hepatitis in mice and subjected the animals to breathe $\mathrm{CO}$ at 500 p.p.m. for $1 \mathrm{~h}$ at various time points after the onset of liver injury. In all cases, CO-treated mice displayed improved survival rates, underscoring the potent therapeutic effects of low-dose $\mathrm{CO}$ exposure. Moreover, these studies suggested time-dependent effects of $\mathrm{CO}$ treatment: the later the application, the worse the outcome. Both studies are in agreement with the results of our present study. Based on our histological results and evaluation of VILI score, we could demonstrate that a delay of $\mathrm{CO}$ inhalation for $3 \mathrm{~h}$ after onset of mechanical ventilation still provides protective effects. It is important to note that the beneficial effects disappear over time (ie, starting $\mathrm{CO}$ inhalation after $5 \mathrm{~h}$ showed no impact on the development of VILI). Surprisingly, significant reduction in cell count, neutrophil fraction, and IL-1 $\beta$ release clearly indicate that CO still exerts anti-inflammatory action, even when the gas was inhaled as late as $5 \mathrm{~h}$ after the onset of mechanical ventilation. The fact that the observed anti-inflammatory effects in this experiment did not translate into organ protection may have several explanations. First, it might be speculated that delayed $\mathrm{CO}$ application on one hand directly inhibits transmigration of pro-inflammatory cells into the lung that would subsequently limit cytokine release at a time point when the inflammatory response is still in process. On the other hand, delayed $\mathrm{CO}$ application might fail to impact the early initiation of other mechanisms independent of pro-inflammatory cascades, for example, stretch-induced signaling. In this case, with the assumption that multiple pathological mechanisms orchestrate VILI, the net effect of delayed CO application would lead to reduction of the inflammatory response without affecting lung injury. Second, these experiments were completed after $6 \mathrm{~h}$ (ie, $1 \mathrm{~h}$ after administration of $\mathrm{CO}$ ). The time from initiation of $\mathrm{CO}$ inhalation to analysis might have been too short to record relevant effects at the organ level. In our experience, neutrophil infiltration in this model is postponed for several hours after the start of mechanical ventilation with moderate tidal volumes. Given the essential role of neutrophils for the progression of VILI and the time-dependent effectiveness of $\mathrm{CO}$, reduction of neutrophils would need to be sustained at least several hours in order to reduce organ injury. Thus, an inhibitory effect on neutrophil transmigration may be detected by neutrophil counts but not necessarily by reduction of organ injury at the time of analysis. Supplementary data provided in this study point in this direction. Extension of $\mathrm{CO}$ inhalation time to 3 or $5 \mathrm{~h}$ starting $5 \mathrm{~h}$ after air ventilation, clearly decreased signs of lung damage as compared with time-matched air-ventilated animals, for 
example, alveolar wall thickening and VILI score. However, there was a tendancy for the anti-inflammatory function of $\mathrm{CO}$ application to decline at later time points.

In conclusion, exposure to low-dose $\mathrm{CO}$ exerts profound protective effects in VILI. In the present study, we provide clear evidence that short-term exposure to $\mathrm{CO}$ beginning at the onset of mechanical ventilation protects against VILI as effectively as long-term inhalation. In contrast to other organs and experimental models, $\mathrm{CO}$ pre-treatment alone does not confer protective or anti-inflammatory effects. However, delayed application of $\mathrm{CO}$ still provides lung protection when inhalation is initiated within $3 \mathrm{~h}$ of mechanical ventilation. Anti-inflammatory effects are conferred even when $\mathrm{CO}$ administration is postponed for $5 \mathrm{~h}$ after the onset of mechanical ventilation.

Supplementary Information accompanies the paper on the Laboratory Investigation website (http://www.laboratoryinvestigation.org)

\section{ACKNOWLEDGEMENTS}

This study was supported by a grant from the Deutsche

Forschungsgemeinschaft (Bonn, Germany) to Alexander Hoetzel (DFG HO 2464/3-1) and a grant from the Forschungsmanagement of the University of Freiburg (Freiburg, Germany) to Alexander Hoetzel (HOET587/07).

\section{DISCLOSURE/CONFLICT OF INTEREST}

The authors declare no conflict of interest.

1. The acute respiratory distress syndrome network. Ventilation with lower tidal volumes as compared with traditional tidal volumes for acute lung injury and the acute respiratory distress syndrome. $\mathrm{N}$ Engl J Med 2000;342:1301-1308.

2. Belperio JA, Keane MP, Lynch III JP, et al. The role of cytokines during the pathogenesis of ventilator-associated and ventilator-induced lung injury. Semin Respir Crit Care Med 2006;27:350-364.

3. Lionetti V, Recchia FA, Ranieri VM. Overview of ventilator-induced lung injury mechanisms. Curr Opin Crit Care 2005;11:82-86.

4. Ricard JD, Dreyfuss D, Saumon G. Production of inflammatory cytokines in ventilator-induced lung injury: a reappraisal. Am J Respir Crit Care Med 2001;163:1176-1180.

5. Gorman D, Drewry A, Huang YL, et al. The clinical toxicology of carbon monoxide. Toxicology 2003;187:25-38.

6. Piantadosi CA. Biological chemistry of carbon monoxide. Antioxid Redox Signal 2002;4:259-270.

7. Maines MD. The heme oxygenase system: a regulator of second messenger gases. Annu Rev Pharmacol Toxicol 1997;37:517-554.

8. SJOSTRAND T. Formation of carbon monoxide in connexion with haemoglobin catabolism. Nature 1951;168:1118-1119.

9. Tenhunen R, Marver HS, Schmid R. The enzymatic conversion of heme to bilirubin by microsomal heme oxygenase. Proc Natl Acad Sci USA 1968;61:748-755.

10. Jin $Y$, Choi AM. Cytoprotection of heme oxygenase-1/carbon monoxide in lung injury. Proc Am Thorac Soc 2005;2:232-235.

11. Ryter SW, Choi AM. Heme oxygenase-1/carbon monoxide: from metabolism to molecular therapy. Am J Respir Cell Mol Biol 2009;41:251-260.

12. Kim HP, Ryter SW, Choi AM. CO as a cellular signaling molecule. Annu Rev Pharmacol Toxicol 2006;46:411-449.

13. Sato K, Balla J, Otterbein L, et al. Carbon monoxide generated by heme oxygenase-1 suppresses the rejection of mouse-to-rat cardiac transplants. J Immunol 2001;166:4185-4194.

14. Boutros $\mathrm{C}$, Zegdi R, Lila $\mathrm{N}$, et al. Carbon monoxide can prevent acute lung injury observed after ischemia reperfusion of the lower extremities. J Surg Res 2007;143:437-442.

15. Fujita T, Toda K, Karimova A, et al. Paradoxical rescue from ischemic lung injury by inhaled carbon monoxide driven by derepression of fibrinolysis. Nat Med 2001;7:598-604.
16. Goebel U, Mecklenburg A, Siepe M, et al. Protective effects of inhaled carbon monoxide in pig lungs during cardiopulmonary bypass are mediated via an induction of the heat shock response. $\mathrm{Br} J$ Anaesth 2009;103:173-184.

17. Otterbein LE, Otterbein $\mathrm{SL}$, Ifedigbo $\mathrm{E}$, et al. MKK3 mitogen-activated protein kinase pathway mediates carbon monoxide-induced protection against oxidant-induced lung injury. Am J Pathol 2003;163: 2555-2563.

18. Wang $\mathrm{X}$, Wang $\mathrm{Y}, \mathrm{Kim} \mathrm{HP}$, et al. Carbon monoxide protects against hyperoxia-induced endothelial cell apoptosis by inhibiting reactive oxygen species formation. J Biol Chem 2007;282:1718-1726.

19. Nemzek JA, Fry C, Abatan O. Low-dose carbon monoxide treatment attenuates early pulmonary neutrophil recruitment after acid aspiration. Am J Physiol Lung Cell Mol Physiol 2008;294:L644-L653.

20. Sarady JK, Zuckerbraun BS, Bilban M, et al. Carbon monoxide protection against endotoxic shock involves reciprocal effects on iNOS in the lung and liver. FASEB J 2004;18:854-856.

21. Faleo G, Neto JS, Kohmoto J, et al. Carbon monoxide ameliorates renal cold ischemia-reperfusion injury with an upregulation of vascular endothelial growth factor by activation of hypoxia-inducible factor. Transplantation 2008;85:1833-1840.

22. Kaizu T, Nakao A, Tsung A, et al. Carbon monoxide inhalation ameliorates cold ischemia/reperfusion injury after rat liver transplantation. Surgery 2005;138:229-235.

23. Nakao A, Toyokawa $H$, Abe $M$, et al. Heart allograft protection with low-dose carbon monoxide inhalation: effects on inflammatory mediators and alloreactive T-cell responses. Transplantation 2006;81: $220-230$.

24. Song R, Kubo M, Morse D, et al. Carbon monoxide induces cytoprotection in rat orthotopic lung transplantation via anti-inflammatory and anti-apoptotic effects. Am J Pathol 2003;163:231-242.

25. Dolinay T, Szilasi M, Liu M, et al. Inhaled carbon monoxide confers antiinflammatory effects against ventilator-induced lung injury. Am J Respir Crit Care Med 2004;170:613-620.

26. Hoetzel A, Dolinay T, Vallbracht $\mathrm{S}$, et al. Carbon monoxide protects against ventilator-induced lung injury via PPAR-gamma and inhibition of Egr-1. Am J Respir Crit Care Med 2008;177:1223-1232.

27. Hoetzel A, Schmidt R, Vallbracht S, et al. Carbon monoxide prevents ventilator-induced lung injury via caveolin-1. Crit Care Med 2009;37: 1708-1715.

28. Volgyesi GA, Tremblay LN, Webster $\mathrm{P}$, et al. A new ventilator for monitoring lung mechanics in small animals. J Appl Physiol 2000;89: 413-421.

29. Sinclair SE, Kregenow DA, Lamm WJ, et al. Hypercapnic acidosis is protective in an in vivo model of ventilator-induced lung injury. Am J Respir Crit Care Med 2002;166:403-408.

30. Belperio JA, Keane MP, Burdick MD, et al. Critical role for CXCR2 and CXCR2 ligands during the pathogenesis of ventilator-induced lung injury. J Clin Invest 2002;110:1703-1716.

31. Quinn DA, Moufarrej RK, Volokhov A, et al. Interactions of lung stretch, hyperoxia, and MIP-2 production in ventilator-induced lung injury. J Appl Physiol 2002;93:517-525.

32. Kim JH, Suk MH, Yoon DW, et al. Inhibition of matrix metalloproteinase-9 prevents neutrophilic inflammation in ventilator-induced lung injury. Am J Physiol Lung Cell Mol Physiol 2006;291:L580-L587.

33. Maniatis NA, Letsiou E, Orfanos $\mathrm{SE}$, et al. Inhaled activated protein $\mathrm{C}$ protects mice from ventilator-induced lung injury. Crit Care 2010; 14:R70.

34. Yang $\mathrm{CL}$, Chen $\mathrm{CH}$, Tsai PS, et al. Protective effects of dexmedetomidine-ketamine combination against ventilator-induced lung injury in endotoxemia rats. J Surg Res 2011;167:e273-e281.

35. Bilban M, Bach FH, Otterbein SL, et al. Carbon monoxide orchestrates a protective response through PPARgamma. Immunity 2006;24:601-610.

36. Goebel U, Siepe M, Schwer Cl, et al. Inhaled carbon monoxide prevents acute kidney injury in pigs after cardiopulmonary bypass by inducing a heat shock response. Anesth Analg 2010;111:29-37.

37. Mishra S, Fujita T, Lama VN, et al. Carbon monoxide rescues ischemic lungs by interrupting MAPK-driven expression of early growth response 1 gene and its downstream target genes. Proc Natl Acad Sci USA 2006;103:5191-5196.

38. Morse D, Pischke SE, Zhou Z, et al. Suppression of inflammatory cytokine production by carbon monoxide involves the JNK pathway and AP-1. J Biol Chem 2003;278:36993-36998. 
39. Zhang X, Shan $\mathrm{P}$, Otterbein LE, et al. Carbon monoxide inhibition of apoptosis during ischemia-reperfusion lung injury is dependent on the p38 mitogen-activated protein kinase pathway and involves caspase 3. J Biol Chem 2003;278:1248-1258.

40. Zhang $X$, Shan $P$, Alam J, et al. Carbon monoxide modulates Fas/Fas ligand, caspases, and $\mathrm{BCl}-2$ family proteins via the p38alpha mitogenactivated protein kinase pathway during ischemia-reperfusion lung injury. J Biol Chem 2003;278:22061-22070.

41. Biermann J, Lagreze WA, Dimitriu C, et al. Preconditioning with inhalative carbon monoxide protects rat retinal ganglion cells from ischemia/ reperfusion injury. Invest Ophthalmol Vis Sci 2010;51:3784-3791.

42. Mazzola S, Forni M, Albertini $M$, et al. Carbon monoxide pretreatment prevents respiratory derangement and ameliorates hyperacute endotoxic shock in pigs. FASEB J 2005;19:2045-2047.

43. Moore BA, Overhaus M, Whitcomb J, et al. Brief inhalation of low-dose carbon monoxide protects rodents and swine from postoperative ileus. Crit Care Med 2005;33:1317-1326.

44. Hieber S, Huhn R, Hollmann MW, et al. Hypoxia-inducible factor 1 and related gene products in anaesthetic-induced preconditioning. Eur J Anaesthesiol 2009;26:201-206.

45. Hu ZY, Liu J. Mechanism of cardiac preconditioning with volatile anaesthetics. Anaesth Intensive Care 2009;37:532-538.

46. Tapuria N, Kumar Y, Habib MM, et al. Remote ischemic preconditioning: a novel protective method from ischemia reperfusion injury-a review. J Surg Res 2008;150:304-330.

47. Goebel U, Siepe M, Mecklenburg A, et al. Reduced pulmonary inflammatory response during cardiopulmonary bypass: effects of combined pulmonary perfusion and carbon monoxide inhalation. Eur J Cardiothorac Surg 2008;34:1165-1172.
48. Kondo-Nakamura $\mathrm{M}$, Shintani-Ishida $\mathrm{K}$, Uemura $\mathrm{K}$, et al. Brief exposure to carbon monoxide preconditions cardiomyogenic cells against apoptosis in ischemia-reperfusion. Biochem Biophys Res Commun 2010;393:449-454

49. Grace PA. Ischaemia-reperfusion injury. Br J Surg 1994;81:637-647.

50. Sakuma T, Takahashi K, Ohya N, et al. Ischemia-reperfusion lung injury in rabbits: mechanisms of injury and protection. Am J Physiol 1999;276:L137-L145.

51. Zimmerman BJ, Granger DN. Mechanisms of reperfusion injury. Am J Med Sci 1994;307:284-292.

52. Guo $Y$, Stein $A B, W u$ WJ, et al. Administration of a CO-releasing molecule at the time of reperfusion reduces infarct size in vivo. Am J Physiol 2004;286:H1649-H1653.

53. Zeynalov $E_{1}$ Dore $S$. Low doses of carbon monoxide protect against experimental focal brain ischemia. Neurotox Res 2009;15: 133-137.

54. Scott JR, Cukiernik MA, Ott MC, et al. Low-dose inhaled carbon monoxide attenuates the remote intestinal inflammatory response elicited by hindlimb ischemia-reperfusion. Am J Physiol 2009;296: G9-G14.

55. Zhou JL, Li G, Hai Y, et al. Protection of carbon monoxide-releasing molecule against lung injury induced by limb ischemia-reperfusion. Chin J Traumatol 2009;12:71-76.

56. Liu SH, Ma K, Xu B, et al. Protection of carbon monoxide intraperitoneal administration from rat intestine injury induced by lipopolysaccharide. Chin Med J (Engl) 2010;123:1039-1046.

57. Tsui TY, Obed A, Siu YT, et al. Carbon monoxide inhalation rescues mice from fulminant hepatitis through improving hepatic energy metabolism. Shock 2007;27:165-171. 